\title{
Assessment of urban sustainability efficiency based on general data envelopment analysis: a case study of two cities in western and eastern China
}

\author{
Yan Yan • Peng Shan • Chenxing Wang • Yuan Quan • \\ Di Wu $\cdot$ Chunli Zhao $\cdot$ Gang Wu $\cdot$ Hongbing Deng
}

Received: 27 June 2016 / Accepted: 26 January 2017 / Published online: 29 March 2017

(C) Springer International Publishing Switzerland 2017

\begin{abstract}
Sustainable urban development focuses on enhancing urban well-being, while also balancing the demands of urban social and economic development, natural resource consumption, and environmental pollution. This work used general data envelopment analysis to assess the urban sustainability efficiency (USE) and sustainability potential (SP) in Lanzhou and Xiamen, two cities that are characteristic of urban areas in western and eastern China. The assessment indicator system included important natural and urban welfare factors as input and output indices, respectively. The results showed that overall urban sustainability efficiency increased in Lanzhou and Xiamen from 1985 to 2010 , but that the sustainability of natural resources clearly decreased. The urban sustainability efficiency of Xiamen was higher than that of Lanzhou, and the sustainability potential of Xiamen was lower than that of Lanzhou; this indicates that Xiamen performed better in
\end{abstract}

\footnotetext{
Y. Yan · P. Shan $\cdot$ C. Wang $\cdot$ Y. Quan $\cdot$ C. Zhao $\cdot$

G. Wu $(\bowtie) \cdot H$. Deng

State Key Laboratory of Urban and Regional Ecology, Research Center for Eco-Environmental Sciences, Chinese Academy of

Sciences, 18 Shuangqing Road, Haidian District, Beijing 100085, People's Republic of China

e-mail:wug@ rcees.ac.cn

P. Shan · C. Wang · Y. Quan · D. Wu • C. Zhao

University of Chinese Academy of Sciences, Beijing 100049,

People's Republic of China

D. Wu

Institute of Urban Environment, Chinese Academy of Sciences,

Xiamen 361021, People's Republic of China
}

terms of urban sustainable development. The urban sustainability efficiency in Xiamen has increased with increasing urban population, and the rate and scale of economic development have been higher than in Lanzhou. The assessment and analysis performed in this study show that cities with different natural resources and development characteristics have different forms, patterns, and trajectories of sustainable development.

Keywords Urban sustainability · Efficiency · Data envelopment analysis $\cdot$ Sustainable development

\section{Introduction}

Urbanization is becoming the main form of social and economic development across the world. It is estimated that the rate of urbanization in developed countries will reach $80 \%$ by 2050 , and that this may happen faster in developing countries (Heinke 1997). While cities, as typical social-economic-natural complex ecosystems, provide various welfare services for their citizens, there is an ever-increasing consumption of natural resources associated with urbanization, as well as an increase in energy inputs and pollutants (Zhao 1999). Accelerated urbanization is accompanied by a series of urban problems, such as the deterioration of urban and surrounding ecological environments, excessive consumption and wastage of natural resources and energy, a decrease in general human well-being, and serious impacts on urban sustainable development (Wu et al. 2014). Many frameworks have been developed to explore urban sustainable 
development, such as the Sustainable Cities Programme in 1991, promoted by UNEP; the Second United Nations Conference on Human Settlements in 1996; and the Habitat Professionals Forum at Urban 21 in 2000 (Bugliarello 2004; Holden et al. 2008). These structures discuss different considerations and methods to encourage urban sustainable development. They pay close attention to sustainable natural resource supply, sustainable protection of urban systems from environmental hazards, and improvement of urban living conditions.

Urban areas need to tackle competing demands at regional and national scale and strike a balance between the irreplaceability of natural resources and the need for social and economic development (Yan et al. 2013). The notion of sustainable urban development demands that economic development should be within tolerable bounds that ensure the protection of natural resources and the environment and that the distribution of resources and social development should be consistent with the premise of social equality (Hedlund-de Witt 2014; Shen et al. 2011). Total and per capita social economic well-being that results from such development should increase, or at least, should not decrease. More importantly, the rate of urban natural resource consumption and ecological and environmental depletion should not be fast (Zhang and Yang 2007; Yan et al. 2005). It should also result in enhanced urban sustainable development efficiency, such that there is a dynamic balance between natural resource consumption and urban social economic well-being (Luo et al. 2013; Liu et al. 2014; Zhao et al. 2016). In this paper, urban sustainability efficiency (USE) is defined as the efficiency between the inputs of the natural system, such as resources and energy, and the output in the form of wellbeing, including social and economic welfare and natural well-being.

As the largest developing country in the world, the nature of development in China will have profound implications on global sustainable development. China is spread across a vast area with clear differences between the western and eastern regions in terms of development and natural resources (Van Dijk and Mingshun 2005). Therefore, these regions also differ in terms of urban development, natural resource consumption, and urban sustainable development. The cities in the eastern regions, especially the coastal cities, which have more economic openness and faster social and economic development, have more natural resources, higher energy consumption, place higher demands on the ecological environment, and consequently cause greater environmental stress (Tang 2013). However, the western cities, located in arid and fragile environmental areas, are relatively slower in terms of urban social and economic development. With the implementation of the Western Development Strategy, urban development has been happening at an accelerated rate, and resource and energy consumption and environmental stress are increasing ( $\mathrm{Si} 2011)$. Urban sustainable development in western and eastern China thus might need to be based on different principles, objectives, and developmental directions (Mori and Christodoulou 2012).

Based on the objectives and principles of urban sustainable development and the framework of sustainable cities, this work considers urban development in China based on typical regional characteristics and establishes a comprehensive assessment indicator system for Chinese urban sustainability efficiency. The latter considers two aspects: the inputs in the form of natural resources and outputs as societal, economical, and natural wellbeing. Two cities, Lanzhou and Xiamen, are chosen as study areas because they are typical of their regions, and demonstrate the regional characteristics and differences between western and eastern China. Based on data envelopment analysis (DEA) and poly-linear programming, we assess the USE of Lanzhou and Xiamen and their sustainability potential (SP) for natural indices. We analyse their performances and scope for improvement through urban natural indices, based on a discussion of the regional differences.

\section{Methods and data}

The assessment indicator system used to calculate USE to measure urban sustainability

Some studies suggest that the goal of urban sustainable development is to construct sustainable cities that effectively balance resource utilization and production and reduce waste to a minimum. This can be achieved by saving resources, increasing use of technology, and improving the environment, thereby reaching a sustainable harmony in terms of resources, nature, society, and the economy in urban systems (Fan 2006; Maclarence 1996). The integrated index system is one of the main methods for assessing sustainable development ( $\mathrm{Li}$ and Zheng 2002). The National Wealth and Green GDP 
index systems from the World Bank are based on environmental monetization (World Bank 1997). The Chinese sustainable development indicator system, proposed by the Sustainable Development Strategy Study Group of the Chinese Academy of Sciences, and the relevant urban sustainable development indicator system, considers resource efficiency and environmental quality as important assessment factors (Luo and Niu 2007). These indicator systems pay close attention to the natural environmental stress from different sources and consider the supportive capacity of ecosystems and the environment to be significant to sustainable development.

Urban development is a multi-system synergistic process that includes various systems such society, the economy, resources, energy, and the environment (Van Dijk and Mingshun 2005; Khodakarami et al. 2014). Factors pertaining to urban development can be categorized as input factors and output factors (Zhao et al. 1999). The main input factors for urban development are materials, information, technology, and direct and indirect capital inputs: for example, water resources, land resources, various forms of energy, technology and capital investment, and natural ecosystem services. The main output factors are direct or indirect materials, well-being services which are available for the operation and development of urban systems, such as the wellbeing of residents, concentrations of pollutants, and urban economic value (see Fig. 1). The relative inputoutput efficiency can be used as a measurement index for urban sustainable development.

To meet the criteria for sustainability in the urban sustainable development assessment, natural resources and energy must be considered irreplaceable and negative impacts of resource consumption and environmental destruction should not arise from economic development (Dietz and Neumayer 2007; Mayer 2008). Development of sustainable cities requires output in the form of improved social, economic, and natural well-being for residents, along with the sustainable use of natural resources and energy and a stable urban ecological environment (Chapman 2014; Rai 2012). In this paper, the USE has been defined as the relative comprehensive efficiency between the natural resource inputs and urban well-being outputs, which has been used to represent urban sustainability. A higher USE indicates better performance in terms of urban sustainability.

The specific index system focuses on basic urban natural resources and energy as its main input indices while ignoring capital and technology related consumption. It includes the main indices used to measure social, economic, and natural aspects of well-being discussed by Wei et al. (2007) and Dong et al. (2013). With regard to the comparison between the cities, most indices are measured per capita, except for life expectancy, Engel's coefficient, and days of 'fairly good' air quality.

Methods

This study uses DEA, which is based on poly-linear programming for calculating the relative efficiencies of multi-input-output systems, to assess the USE of Lanzhou and Xiamen (Yin et al. 2014; Chen et al. 2011). The basic mathematical method involves estimating the poly-linear programming model based on an assessment of the sampled data from the two cities and assessing the relative efficiencies of the designated samples, called the decision Making Units (DMU) (Toloo and Tichý 2015). The DEA efficiency is calculated by finding the relative distance of a DMU to the optimal hyperplane, which is estimated using the poly-linear programming model (Zerafat Angiz et al. 2015). If the efficiency of a DMU is 1 , which is in the optimal hyperplane, it means that under the current input system, the DMU could not have higher system efficiency by improving the performance of any of the output factors, unless the performance of other output factors is reduced (Huguenin 2015; Podinovski and Bouzdine-Chameeva 2015). A high USE value for a city indicates that the resource and energy consumption and pollutant emissions in that city are less than the other cities with an equivalent amount of urban social and economic welfare and residents' well-being; it also shows that for an equivalent amount of resource and energy consumption and pollutant emissions, this city has a higher output in the form of urban social and economic welfare and residents' well-being. These are essentially the main objectives of urban sustainable development.

This method can also be used to calculate the SP of all the indices, which is defined as the relative distance between the indices of one DMU and the optimal hyperplane, based on DEA. The SP of the input indices is the ratio between the ideal demand and actual consumption of natural resources and energy. The SP of the input indices helps measure the excess input, which is essentially the gap between the urban natural resource and energy inputs and pollutant emissions and urban social and economic outputs. The SP of the output indices is 


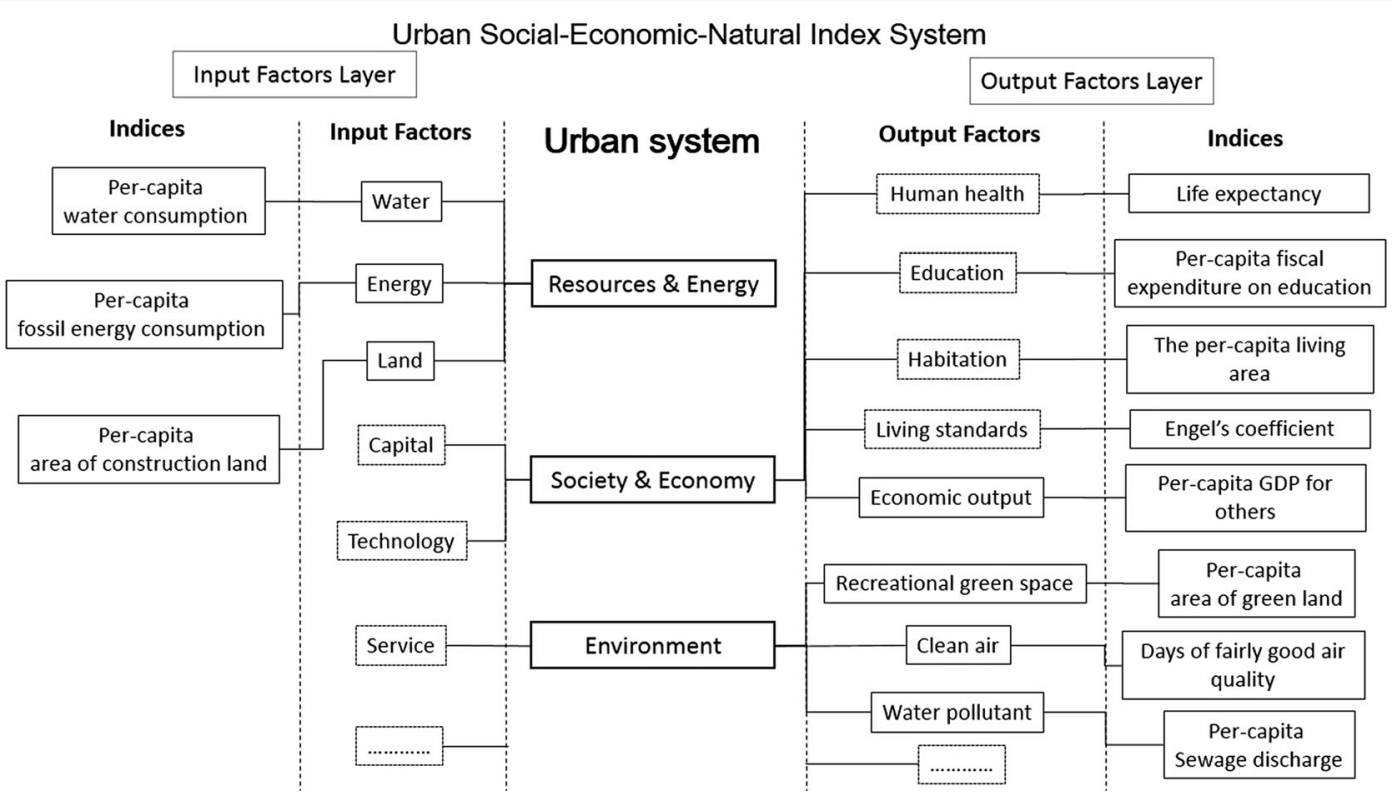

Fig. 1 The comprehensive index system used to calculate USE in order to measure urban sustainability

the proportion between the ideal and actual urban wellbeing output, which basically indicates the gap between the actual performance in terms of the societal urban well-being, economy, ecology, and environment and the theoretical optimal performance. Furthermore, although DEA could be used to calculate the SP of all the indices, considering the significance of natural indices in urban sustainable development and the actual meaning of SP, this study focuses on the SP of natural indices, such as water, energy, and land resources, as well as urban green space.

\section{Study areas}

Lanzhou, the capital of Gansu province, and Xiamen, which are representative of cities in western and eastern China, respectively, are the study areas examined in this research. Lanzhou is located in northwest China and runs along the Yellow river. With a narrow river valley, Lanzhou has very limited available land resources; the per capita urban land area is only about $172 \mathrm{~m}^{2}$. The average annual precipitation of Lanzhou is lower than $400 \mathrm{~mm}$, at about $327 \mathrm{~mm}$; therefore, it does not have enough water resources, and the availability of such resources is lower than the national average (see Fig. 2).

However, Xiamen, mostly located on Xiamen Island, is a typical Chinese eastern coastal city with abundant water resources; the average annual precipitation is $1143 \mathrm{~mm}$. Xiamen also has limited available land resources, and the per capita urban land area there is $481 \mathrm{~m}^{2}$. With the implementation of the integrative development strategy of Xiamen-Zhangzhou-Quanzhou, the size of Xiamen has increased and it has spread across the surrounding areas.

Both cities are significant for transportation in western and eastern China; Lanzhou is the transport node in the national Silk Road Economic Belt, and Xiamen is an important port for foreign trade in the South-East coastal areas of China. In the past three decades, Lanzhou and Xiamen have seen palpable increases in terms of population and economy; however, the rate of this increase has been much higher in Xiamen.

\section{Data resources}

The main data source used was the China City Statistical Yearbook, the Chinese City Construction Statistical Yearbook, and statistical and environmental monitoring data (such as indicators like the number of days of 'fairly good' air quality) obtained from the Chinese Ministry of Environmental Protection and the Chinese Ministry of Housing and Urban-Rural Development. Data were collected from 1985 to 2010 . About $90-95 \%$ of the data used in this study are statistical data, and the remainder are actual monitoring data. 


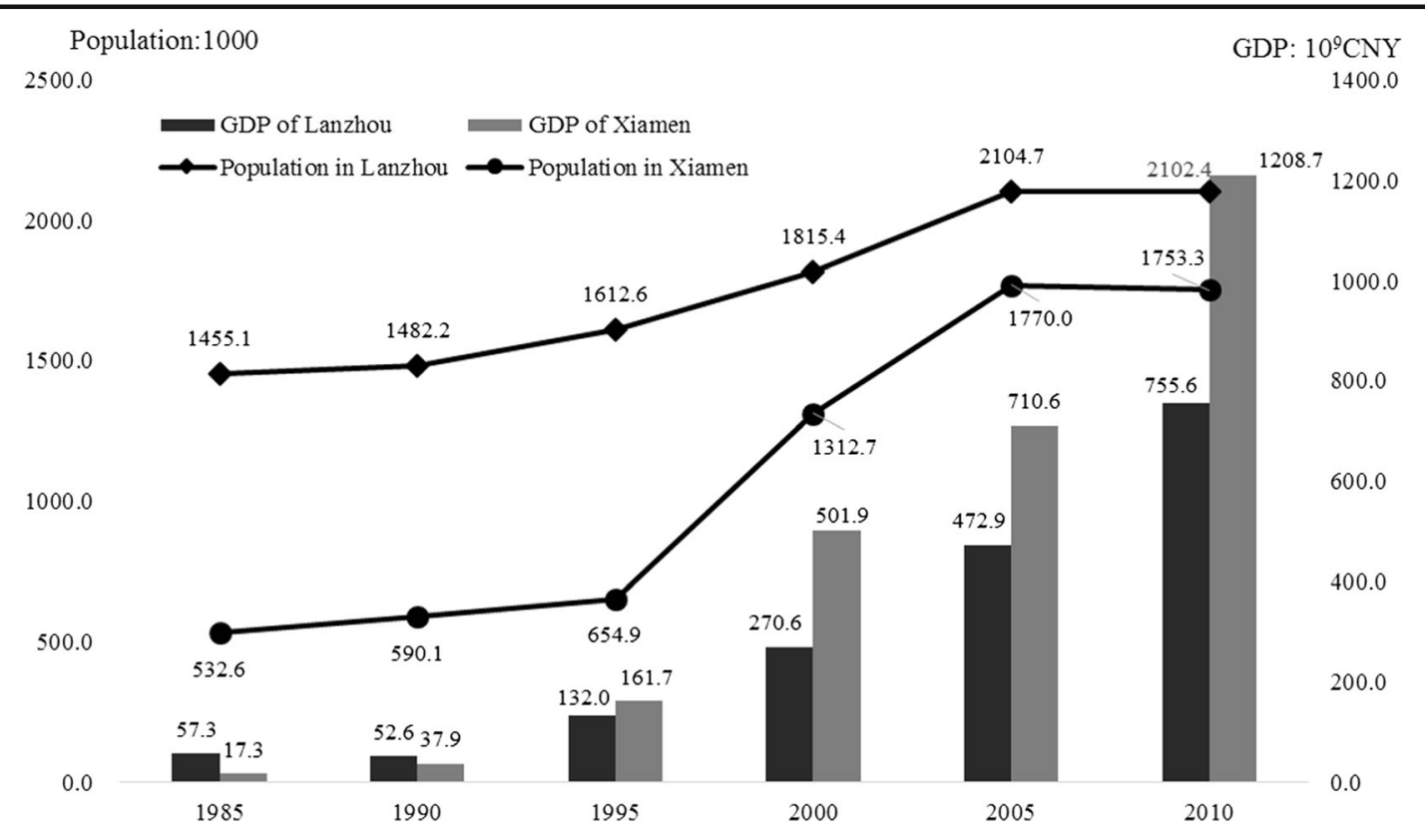

Fig. 2 The population and GDPs of the assessment cities

\section{Results}

The USE of Lanzhou and Xiamen

The assessment results of urban sustainability efficiency (USE) are shown in Fig. 3. As can be seen, the USE of Lanzhou and Xiamen clearly increases over the period from 1985 to 2010. The rate of this increase in Lanzhou $(0.099-0.269)$ is much lower than that in Xiamen (0.196-0.764). From 1985 to 1995 , the two cities had similar USE and the increase was slow; however, after 1995, the USE of Xiamen showed a rapid increase, while that of Lanzhou showed a slower increase. Along with increasing population and GDP, economic development in Xiamen has been increasing rapidly. Therefore, the USE of Xiamen also increased rapidly. This shows that urban development in Xiamen is moving in a relatively more sustainable direction, while this is occurring more slowly in Lanzhou.

The SP of natural indices

Considering the irreplaceability of natural resources, this study focuses on the assessment of the SP of natural indices, including input indices, such as water, energy, and land resources, and one output index, urban green space (see Table 1). That fact that the SP of all the natural indices decreased over the study period indicates that the performance of natural indices in Lanzhou and Xiamen has shown improvement in terms of urban sustainability. However, the SP was always highest for energy among all the input indices, which means that it is an important impact index for USE in Lanzhou and Xiamen and that improving energy efficiency should be a critical consideration for their sustainable development. The performance of urban green space output also exhibited obvious improvement from 1985 to 2010. A comparison of the two cities shows that the SP of each index for Lanzhou decreased less than that of Xiamen; the same gap was reflected in terms of the USE in Lanzhou and Xiamen.

The distance from the optimal sustainability hyperplane as measured by DEA, representing the difference between the ideal and actual values of indices, is shown in Fig. 4. In this figure, the polygonal line shows the actual value of each natural index, and the histogram represents their distance from sustainable values, as measured by the USE. The absolute values and the difference between ideal and actual values for water and land area have similar performances according to their SP. However, although the SP of energy shows a decreasing tendency, the amount and distance from sustainable values increase from 1985 to 2010. Lanzhou and Xiamen need to make considerable effort to reduce absolute energy consumption. Although the actual area of green space has increased since 1985, these do not meet the USE demand. 


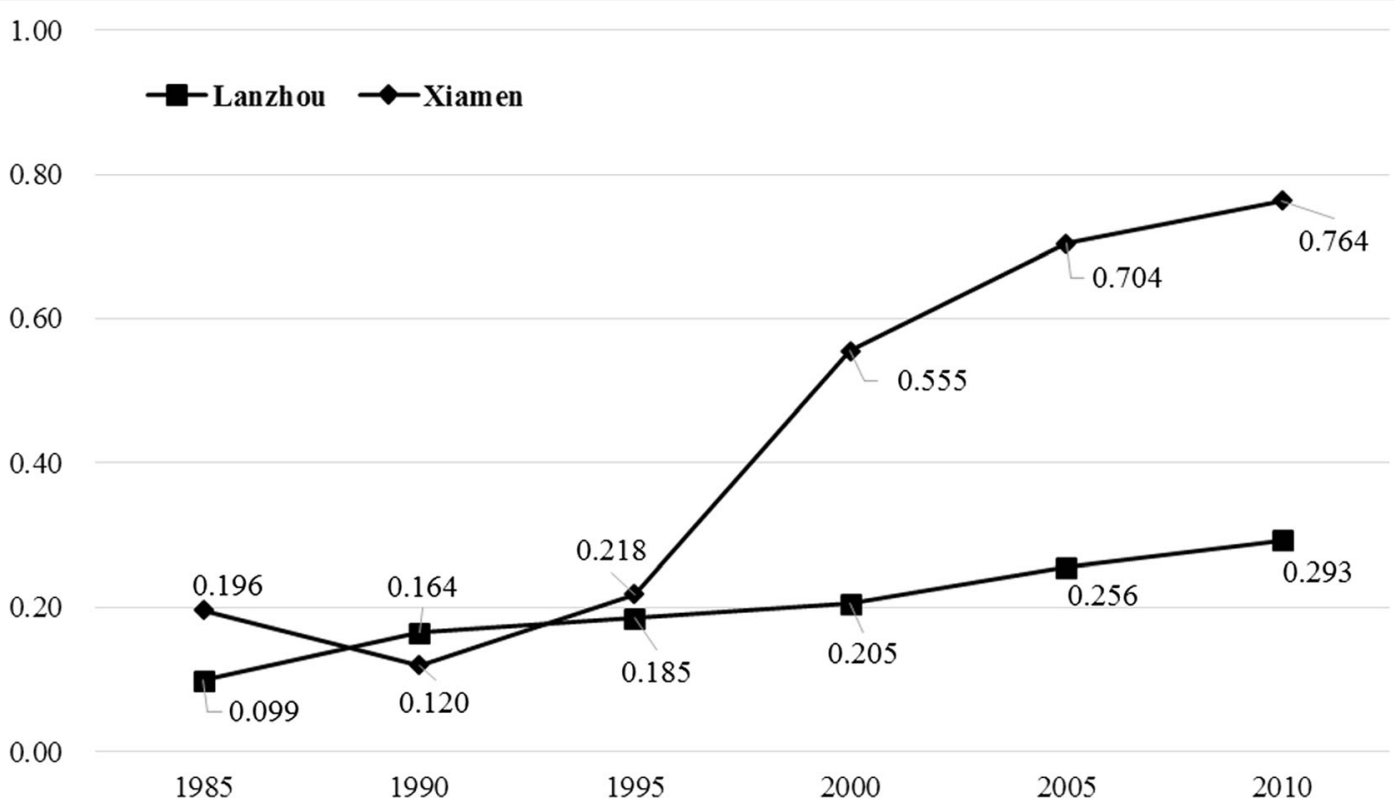

Fig. 3 The USE of Lanzhou and Xiamen showing their progression towards urban sustainability

\section{Discussion}

The impact of population and economy on USE and natural input factors

Population aggregation and economic development are the most important characteristics of urban development. Changes in urban population and economic scale would impact the factors that drive urban sustainable development. With different social, economic and natural characteristics, and different directions of urban sustainable development and development stages, population aggregation and economic development will have different impacts on USE and related factors. In this study, the urban population is a measurement index of the urban population scale, and the GDP is used to measure urban economic scale. The USE of Lanzhou and Xiamen have increased with the rise in urban population and GDP (see Fig. 5), and Xiamen's USE increased at a faster rate than that of Lanzhou.

The impact of population and economy on natural input factors

This study also analysed the relationships between and the impact of urban population and economic scale on the main natural input factors: water, energy, and land resources (see Fig. 6). The relationship between water, energy, and urban population is similar to the inverted u- shaped curve of the environmental Kuznets curve. Although the SP of water resources in Lanzhou is higher than that in Xiamen, the decreasing tendency of water resources with increasing urban population is much more obvious. Considering the difference in water resource conditions between the two cities, urban sustainable development has different demands on water consumption, and a city with abundant water resources may have more development opportunities and fewer restrictions on water consumption. The relationship between population and energy use in Xiamen is an inverted $\mathrm{u}$ shaped curve on which the turning point has been reached, with the population now increasing, while the trend in Lanzhou still shows an increasing tendency. The urban development of Xiamen has been limited by energy efficiency restrictions driving change towards

Table 1 The SP of natural indices

\begin{tabular}{llllllll}
\hline Cities & Indices & 1985 & 1990 & 1995 & 2000 & 2005 & 2010 \\
\hline Lanzhou & Water & 0.95 & 0.96 & 0.93 & 0.89 & 0.79 & 0.72 \\
& Energy & 0.95 & 0.95 & 0.90 & 0.89 & 0.89 & 0.89 \\
& Land & 0.95 & 0.95 & 0.90 & 0.89 & 0.79 & 0.72 \\
& Green space & 17.71 & 17.71 & 8.59 & 7.95 & 3.71 & 2.61 \\
Xiamen & Water & 0.81 & 0.94 & 0.86 & 0.60 & 0.77 & 0.43 \\
& Energy & 0.81 & 0.86 & 0.78 & 0.40 & 0.77 & 0.59 \\
& Land & 0.81 & 0.86 & 0.78 & 0.40 & 0.77 & 0.43 \\
& Green space & 4.14 & 6.34 & 3.64 & 0.95 & 3.39 & 0.75 \\
\hline
\end{tabular}



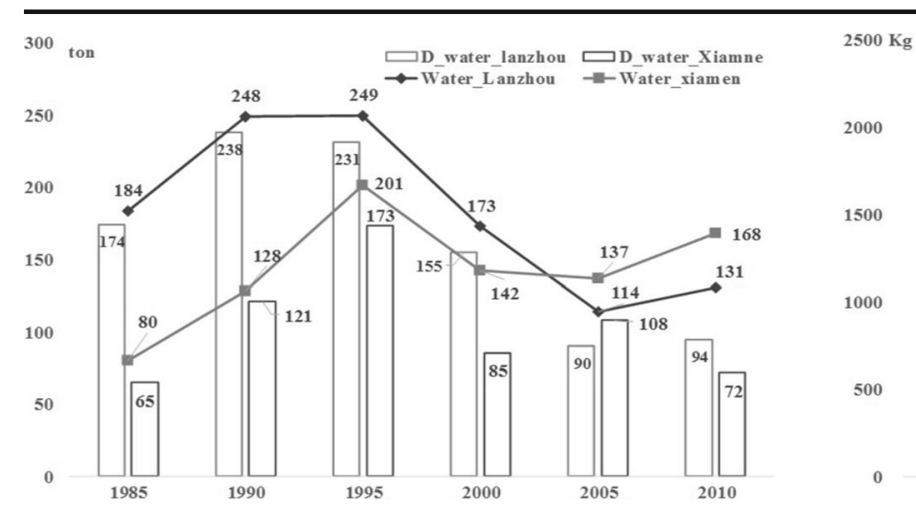

$\square$ D_energy_Lanzhou $\square$ D_energy_Xiam en
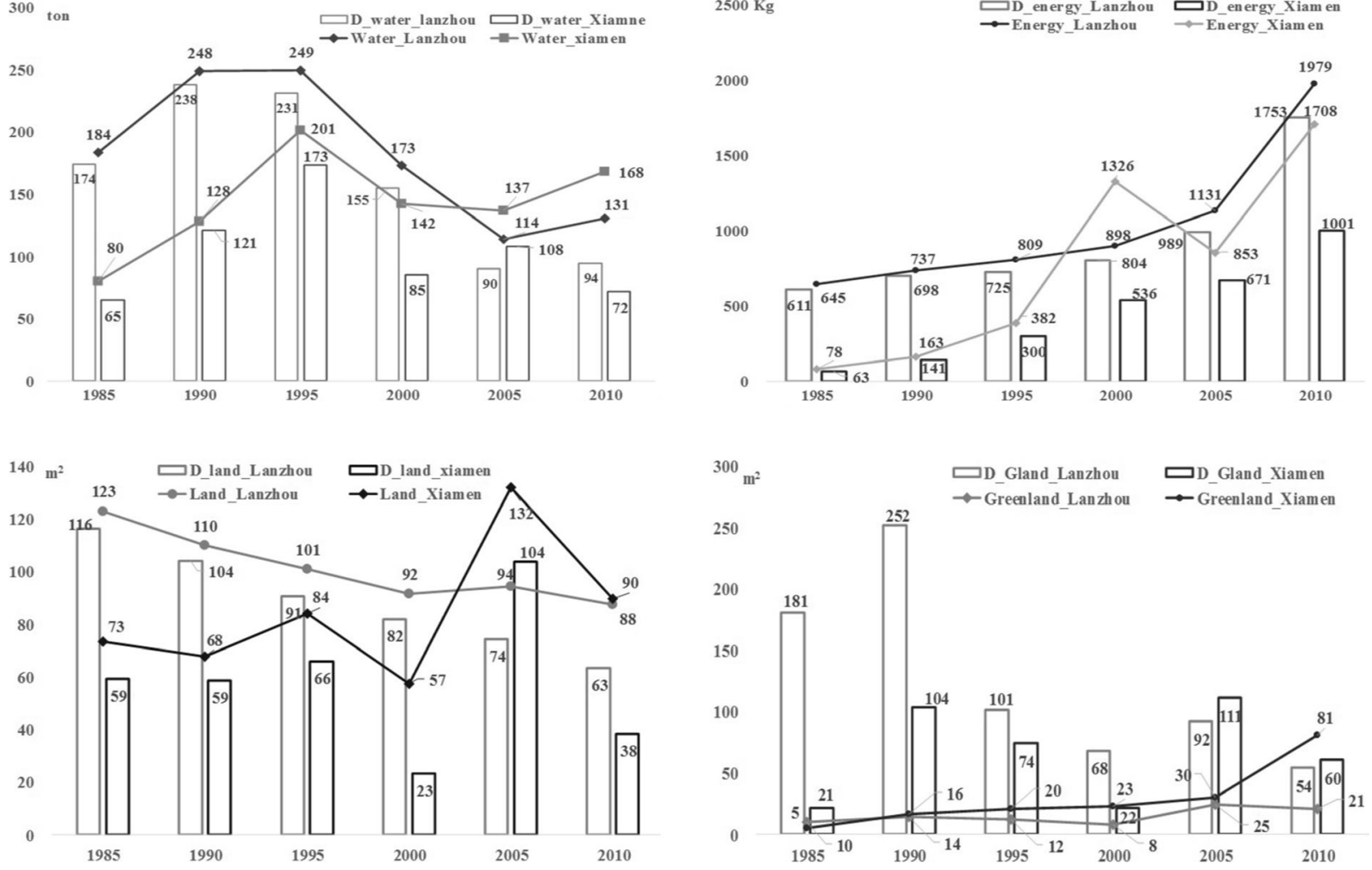

Fig. 4 The difference between the actual performance of input indices and their ideal effective and sustainable performance in Lanzhou and Xiamen

sustainable energy use, but the urban development of Lanzhou is still driven by high energy use.

The relationship between urban economic scale and water, energy, and land also exhibits obvious differences between western and eastern regions with respect to urban development (see Fig. 7). The intensity of water and land resource consumption has decreased with increasing urban GDP in Lanzhou, whereas the inverse is true for Xiamen. Taking the example of land resources, with the integrative development strategy of XiamenZhangzhou-Quanzhou, a large amount of land outside of Xiamen Island is now included within the urban boundary of Xiamen, which has more abundant land resources than Lanzhou. However, because of limitations in water and land resources, Lanzhou has followed more efficient and compact development patterns, which have had a positive effect on urban sustainable development and on reducing excess land consumption.
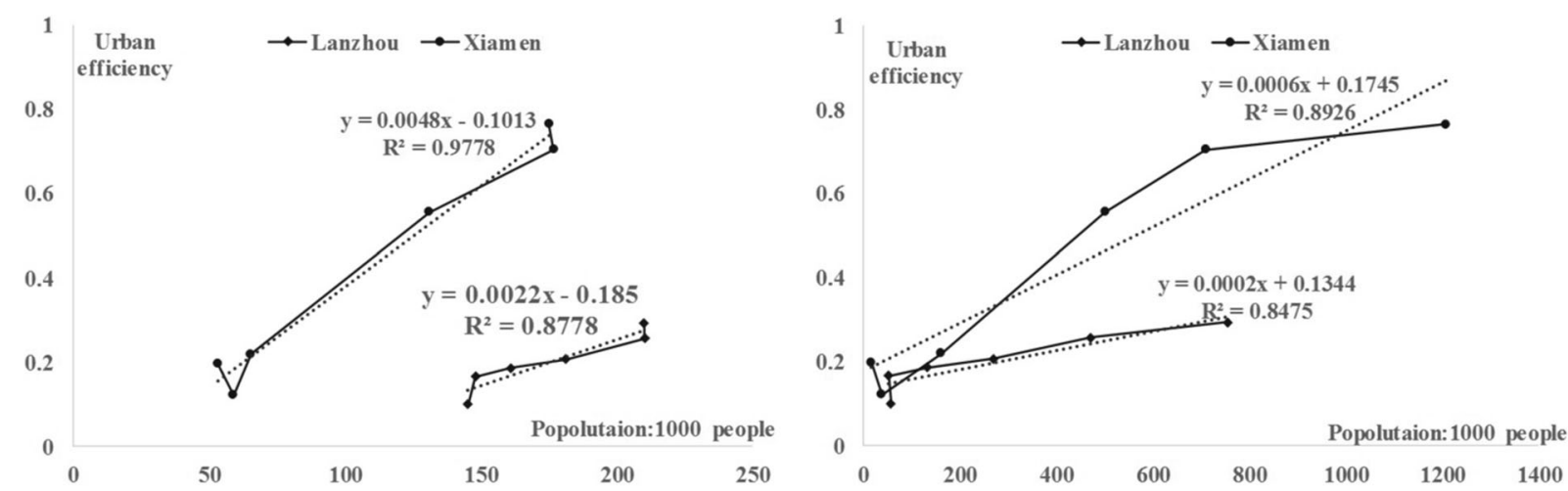

Fig. 5 The relationship between population, GDP, and USE of Lanzhou and Xiamen 

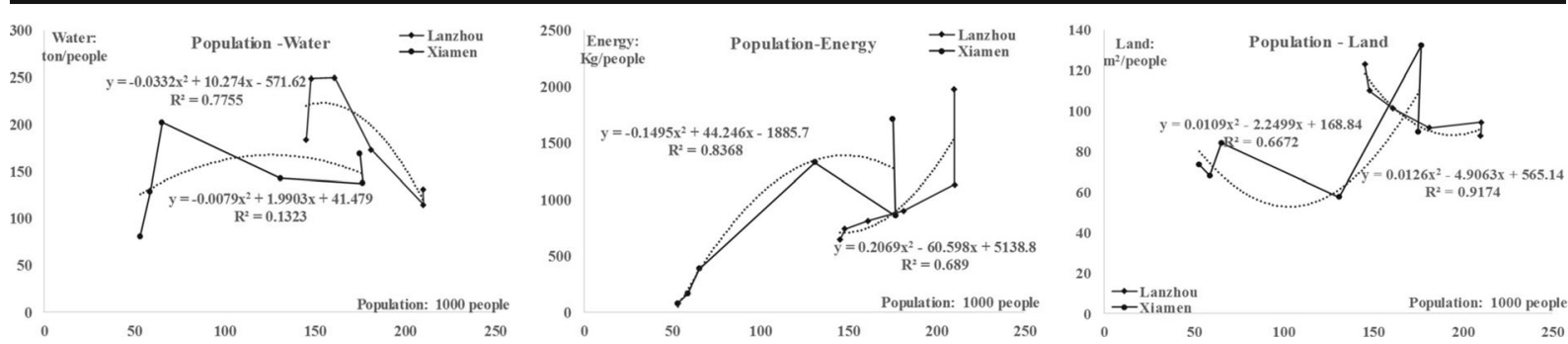

Fig. 6 The relationship between population and input indices in Lanzhou and Xiamen

Data uncertainty analysis

The data used in this research are mainly statistical data, and hence the main error in the data would likely come from changes in quality or measurement standards, which may lead to an inter-annual difference in the assessment data. For example, although the USE of Xiamen since 2005 has been increasing, the SP of natural factors has all obviously increased. This may be an error caused by statistical calibration changes because the administrative regional planning involved an important readjustment wherein the urban boundary was changed. However, the USE and SP assessment results still reflect the basic characteristics and trends of urban sustainable development of Lanzhou and Xiamen and the regional differences. Therefore, the assessment method, data, and results can be considered reliable and certain on this basic level.

\section{Conclusion}

Based on DEA, this study assessed the USE of Lanzhou and Xiamen, two cities in western and eastern China. The assessment results showed that the USE of Lanzhou and Xiamen increased during 1985 to 2010, and the performance of the USE in Xiamen was better than in Lanzhou. The SP of energy was the highest of all the natural input factors. The SP of each natural factor in Lanzhou was higher than their equivalent factors in Xiamen, which means that Lanzhou should take more efforts to improve the integrative efficiency between its urban input and output factors to achieve urban sustainability.

There was an obvious increase in the USE of Lanzhou and Xiamen with an increase in urban population and economic scale, and the USE of Xiamen increased faster than that of Lanzhou. There were regional differences in the relationship between urban population and economic scale and water, energy, and land resources. The water and land consumption in Xiamen increased with the increase in urban population and economic scale, whereas the opposite was true for Lanzhou. The SP of water and land in Lanzhou was still higher than in Xiamen. The relationship between energy consumption in Xiamen and urban population and economic scale was an inverted u-shaped curve, but the same relationship in Lanzhou still showed an increasing tendency.

According to the USE assessment and analysis in Lanzhou and Xiamen, it is evident that these two cities have different sustainable development characteristics and trajectories because of differences in natural resources and urban social and economic development characteristics. Located in the northwest arid areas and with space limitations due to its location in the Yellow river valley, the urban development of Lanzhou is limited by the availability of water and land resources. However, further urban social and economic development is needed to improve residents' well-being. Sustainable development planning in Lanzhou should focus on how to improve resource and energy efficiency and
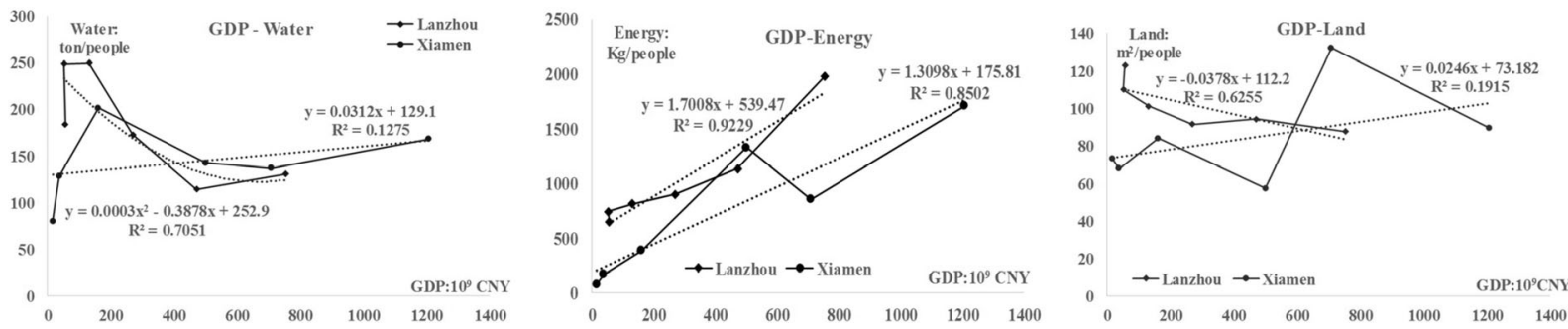

Fig. 7 The relationship between urban economy and input indices in Lanzhou and Xiamen 
achieve urban economic development. With abundant water and land resources and higher urban economic welfare, sustainable development planning in Xiamen should emphasize reducing natural resource and energy consumption while maintaining and improving the current level of urban social and economic welfare.

This study on the USE and sustainable development potential of Lanzhou and Xiamen will help identify directions and objectives for sustainable development and provide theoretical and quantitative support for the strategic formulation of urban sustainable development in such cities. The differences between Lanzhou and Xiamen in this study could partly reflect the differences in the sustainable development of similar cities in western and eastern China. However, these two cities could not completely represent all the characteristics of western and eastern cities. To further determine the differences and characteristics of sustainable development in western and eastern China, more research is needed into the theoretical and practical applications of sustainable development.

Acknowledgements This study was supported by the National Key Technologies R\&D Program of China (Grant No. 2016YFC0502102) and the National Natural Science Foundation of China (Grant No. 71673268). The authors are grateful to all the people who helped complete this research and the anonymous reviewers for their suggestions on the manuscript.

Author contributions Yan Yan, Chenxing Wang, and Peng Shan conceived and designed the study; Yan Yan conceptualized the paper and completed the English writing; and Chenxing Wang contributed to data collection, calculation, and results analysis. Yuan Quan and Di Wu contributed to the conceptual model. Chunli Zhao, Gang Wu, and Hongbing Deng contributed to manuscript revision. All authors read and approved the submitted manuscript, agreed to be listed, and accepted the version for publication.

\section{Compliance with ethical standards}

Conflicts of interest The authors declare that they have no conflict of interest.

\section{References}

Bugliarello, G. (2004). Urban sustainability: science, technology and policies. Journal of urban technology, 11, 1-11.

Chapman, S. (2014). A framework for monitoring social process and outcomes in environmental programs. Evaluation and Program Planning, 47, 45-53.
Chen, Y., Chen, C.-Y., \& Hsieh, T. (2011). Exploration of sustainable development by applying green economy indicators. Environmental Monitoring and Assessment, 182(1), 279289.

Dietz, S., \& Neumayer, E. (2007). Weak and strong sustainability in the SEEA: concepts and measurement. Ecological Economics, 61, 617-626.

Dong, R., Tang, M., Zhou, K., et al. (2013). Study on the modified quadrat sampling method for urban ecosystem network monitoring. International Journal of Sustainable Development \& World Ecology, 20, 210-215.

Fan, S. (2006). Theoretical analysis on the increasing process of urban sustainability. Economic Geography, 26, 961-965.

Hedlund-de Witt, A. (2014). Rethinking sustainable development: considering how different worldviews envision "development" and "quality of life". Sustainability, 6, 8310-8328.

Heinke, G. W. (1997). The challenge of urban growth and sustainable development for Asian cities in the 21 st century. Environmental Monitoring and Assessment, 44(1), 155-171.

Holden, M., Roseland, M., Ferguson, K., \& Perl, A. (2008). Seeking urban sustainability on the world stage. Habitat International, 32, 305-317.

Huguenin, J.-M. (2015). Data envelopment analysis and nondiscretionary inputs: how to select the most suitable model using multi-criteria decision analysis. Expert Systems with Applications, 42, 2570-2581.

Khodakarami, M., Shabani, A., \& Farzipoor Saen, R. (2014). A new look at measuring sustainability of industrial parks: a two-stage data envelopment analysis approach. Clean Technologies and Environmental Policy, 16, 1577-1596.

Li, L., \& Zheng, D. (2002). Regional sustainable development assessment: progress and outlook. Progress in Geography, 21, 237-248.

Liu, H., Zhou, G., Wennersten, R. F., et al. (2014). Analysis of sustainable urban development approaches in China. Habitat International, 41, 24-32.

Luo, Y., \& Niu, W. (2007). The overview of China's sustainable development: pandect of China's sustainable development (volume 1). Beijing: Science Press.

Luo, N., Li, J., \& Luo, F. (2013). Empirical analysis on the relationship between the China urbanization and regional eco-efficiency. China Popilation, Resources and Environment, 23, 53-60.

Maclarence, V. W. (1996). Urban sustainability reporting. Journal of the American Planning Association, 02, 185-202.

Mayer, A. L. (2008). Strengths and weaknesses of common sustainability indices for multidimensional systems. Environmental International, 34, 277-291.

Mori, K., \& Christodoulou, A. (2012). Review of sustainability indices and indicators: towards a new city sustainability index (csi). Environmental Impact Assessment Review, 32, 94-106.

Podinovski, V. V., \& Bouzdine-Chameeva, T. (2015). Consistent weight restrictions in data envelopment analysis. European Journal of Operational Research, 244, 201-209.

Rai, P. K. (2012). An eco-sustainable green approach for heavy metals management: two case studies of developing industrial region. Environmental Monitoring and Assessment, 184, 421-448. 
Shen, L. Y., Jorge Ochoa, J., Shah, M. N., et al. (2011). The application of USE indicators - a comparison between various practices. Habitat International, 35, 17-29.

$\mathrm{Si}$, L. (2011). Study on the ecological compensation mechanism in Gansu. Lanzhou: Lanzhou University.

Tang, H. (2013). The coastal cities evolution of land use and regional ecological environmental quality research during urbanization-taking Shandong Province as an example. Shenyang: Liaoning Normal University.

Toloo, M., \& Tichý, T. (2015). Two alternative approaches for selecting performance measures in data envelopment analysis. Measurement, 65, 29-40.

Van Dijk, M. P., \& Mingshun, Z. (2005). Sustainability indices as a tool for urban managers, evidence from four medium-sized Chinese cities. Environmental Impact Assessment Review, 25, 667-688.

Wei, J., Zhao, Y., Xu, H., et al. (2007). A framework for selecting indicators to assess the sustainable development of the natural heritage site. Journal of Mountain Science, 4, 321-330.

World Bank (1997). Expanding the measure of wealth: Indicators of environmentally sustainable development. Washington, D C.

Wu, J., He, C., Zhang, Q., et al. (2014). Integrative modeling and strategic planning for regional sustainability under climate change. Advances in Earth Science, 29, 1315-1324.

Yan, Y., Yu, L., Chen, S., et al. (2005). The capital connotation of sustainable development and relation analysis. Scientifit Progress and Countermeasures, 12, 27-29.
Yan, Y., Jia, J., Zhou, K., et al. (2013). Study of regional water footprint of industrial sectors: the case of Chaoyang City, Liaoning Province, China. International Journal of Sustainable Development \& World Ecology, 20, 542-548.

Yin, K., Wang, R., An, Q., et al. (2014). Using eco-efficiency as an indicator for sustainable urban development: a case study of Chinese provincial capital cities. Ecological Indicators, 36, 665-671.

Zerafat Angiz, L. M., Mustafa, A., Ghadiri, M., et al. (2015). Relationship between efficiency in the traditional data envelopment analysis and possibility sets. Computers \& Industrial Engineering, 81, 140-146.

Zhang, Y., \& Yang, Z. (2007). Energy analysis of urban material metabolism and evaluation of eco-efficiency in Beijing. Acta Scientiae Circumstantiae, 27, 1892-1899.

Zhao, J. (1999). The critical analysis on the measurement of sustainable development of social-economic-natural complex ecosystem. Acta Ecologica Sinica, 15, 327-330.

Zhao, J., Liang, X., \& Zhang, X. (1999). System analysis on the definition of sustainable development. Acta Ecologica Sinica, 19, 393-399.

Zhao, J., Liu, X., Dong, R., \& Shao, G. (2016). Landsenses ecology and ecological planning toward sustainable development. International Journal of Sustainable Development \& World Ecology, 23(4), 293-297. 